\title{
Causal Relationship between Electricity Consumption and GDP: Plausible Explanation on Previously Found Inconsistent Conclusions for India
}

\author{
Shashi Kant Srivastava \\ Indian Institute of Management, Indore, India \\ Email:f13shashis@iimidr.ac.in
}

Received 5 March 2016; accepted 24 April 2016; published 27 April 2016

Copyright (C) 2016 by author and Scientific Research Publishing Inc. This work is licensed under the Creative Commons Attribution International License (CC BY). http://creativecommons.org/licenses/by/4.0/

\section{c) (i) Open Access}

\begin{abstract}
Using cross-state panel data and error correction Granger causality model we found trustworthy results for India that were non-consistent in previous literature. We found that the electricity consumption and per capita income cause each other. We argue our research to be more credible because we use 254 data points whereas, previous researchers have given their conclusions only on 30 - 40 data points. There is feedback effect of both the variables and effect of electricity consumption is $\mathbf{4 0}$ times more than that of income to electricity. Furthermore, analysis at disaggregated level of electricity consumption suggests that domestic and heavy industry electricity consumption causes income growth and not the commercial, light industry, and agricultural electricity consumption.
\end{abstract}

\section{Keywords}

Electricity Consumption, Panel Granger Causality, Error Correction Model, Indian States

\section{Introduction}

In the Indian context, there are conflicting results of causality direction between electricity and GDP. Many researchers have found electricity consumption (EC) to cause GDP [1]-[3]. Many other researchers have proved GDP to cause EC [4]-[6]. Whereas, some concluded this relationship in both the direction [7] [8] and some more found that there is no causality relationship between EC to GDP [3] [9]. Many of these conclusions are reported at one place by [10]. Therefore, all possible combinations of causality are found and reported for India. India is a 
vast and heterogeneous country that accommodates more than one-seventh of the earth population. The population of India's biggest state Uttar Pradesh is more than any other country except China, India, US, Indonesia, and Brazil [11]. Even its smallest state Sikkim's population is more than 22 nations of the world [12]. All the studies mentioned above use a limited number of data points maximum up to 40 . A limited number of data points and studies at the aggregate level without integrating the internal diversity are one of the obvious reasons for inconsistent findings [13]. By neglecting individual heterogeneity, we can’t get an explicable relationship between economic aggregates [14]. Existing literature on this issue in the Indian context has ignored the study at the disaggregate level. We fill this gap by studying this phenomenon within India, across its various states and try to find the true relationship. Literature supports that if overall level is giving a conflicting result, it may be because of aggregation bias and therefore, granular level study may be conclusive [15]. Furthermore, study at the state level will increase the number of data points that may lead to a robust conclusion.

With electricity consumption from the year 2001 till 2013, we used cross-state panel data to analyze the ECGDP nexus. In state context, we use per capita income in the state as quasi for per capita GDP. In Section 2, we denote the equations used to address the causality. In Section 3, we perform several estimations for the causality testing. Section 4 concludes the paper.

\section{Literature Review}

There is a substantial amount of literature that examines the granger causality relationship between electricity consumption and GDP. However, due to the importance this subject holds for society, literature is still growing. At the global level, there is no singular trend observed [6]. The literature on electricity consumption and economic development has concluded all the possible relationships i.e. growth, conservation, neutrality, and feedback [6]. Growth hypothesis suggests that electricity consumption leads to economic development. A conservation hypothesis is opposite to the growth hypothesis and proposes that it is economic development that is responsible for the growth in electricity consumption. Neutrality assumption advocate independence of both the variables and feedback supposition suggest interdependence of both the variables on each other. All possible conclusions at global as well as country level suggest that there are potential gaps in this research area that needs to be bridged. Aggregation of data is one of the obvious gaps [16]. For the purpose of our analysis, we disaggregate the information's at two levels. One, instead of data at aggregated country level we disaggregate it at the level of states. Two, we disaggregate the electricity consumption based on the nature of electricity consumption. Therefore, we also study the relationship at the disaggregate level of EC such as domestic, commercial, industrial, and agricultural. Furthermore, the study of differentiated electricity consumption is advised to be conducted by some researches [16]. Following the above-mentioned literature review we ultimately propose to answer the following research questions.

Research Question 1: What is the causality direction between EC to GDP for disaggregated geographical levels for India?

Research Question 2: Which is or are the significant EC influencer of this relationship domestic, commercial, industrial, or agricultural?

\section{Model}

We set the following Granger causality equations for various estimations. We use error correction method. We adopt only one lag in causality equation because most of the previous literature have found short term causality between these two variables in Indian context [1] [5]. We also found only one lag correlations for both the variables in our PACF plot. In the first step, we de-trend the data and establish the stationarity. After establishing the stationarity, error correction term (ECT) is calculated as explained in Equation (2). Lag ECT is used to eliminate the misspecification of the two variable causality model [17] [18]. Equation (3) presents the EC to income Granger causation computation. In a similar manner, all the three equations are used for reverse causation and Equation (6) demonstrate the income to EC causation estimation.

\subsection{EC to Income Causation Equations}

$$
\text { Income }_{i t}=\beta_{0}+\beta_{2} \text { Time }_{i}+\text { unexplained_income }(U I)_{i t}
$$




$$
\begin{aligned}
\mathrm{UI}_{i t} & =\beta_{0}+\beta_{1} \mathrm{EC}_{i t}+\text { error_correction_term }\left(\mathrm{ECT}_{i t}\right) \\
\mathrm{UI}_{i t} & =\beta_{0}+\beta_{1} \mathrm{Income}_{i(t-1)}+\beta_{2} \mathrm{EC}_{i(t-1)}+\beta_{3} \mathrm{ECT}_{i(t-1)}+u_{i t}
\end{aligned}
$$

\subsection{Income to EC Causation Equations}

$$
\begin{aligned}
& \left.\mathrm{EC}_{i t}=\beta_{0}+\beta_{2} \text { Time }_{i}+\text { unexplained_eclectricity_consumption(UEC }\right)_{i t} \\
& \mathrm{UEC}_{i t}=\beta_{0}+\beta_{1} \mathrm{Income}_{i t}+\text { error_correction_term }\left(\mathrm{ECT}_{i t}\right) \\
& \mathrm{UEC}_{i t}=\beta_{0}+\beta_{1} \mathrm{Income}_{i(t-1)}+\beta_{2} \mathrm{EC}_{i(t-1)}+\beta_{3} \mathrm{ECT}_{i(t-1)}+u_{i t}
\end{aligned}
$$

where $u_{i t}=\eta_{i}+\varepsilon_{i t}$, $\eta_{i}$ is an individual (state) fixed effect and $\varepsilon_{i t}$ is independently and identically distributed error among states and years. We have not included time effect in the equation since time effect is already captured in causation. The income ${ }_{i t}$ is the real per-capita income of state $i$ at year $t . \mathrm{EC}_{i t}$ is the per capita electricity consumption in $\mathrm{Kw} \mathrm{H}$ /year. All the explained six equations are used for three types of panel data model. Pooled model, that is parallel to aggregate model, fixed effect model, and random effect model. Furthermore, with the help of Hausman test we conclude the best model for our data.

\subsection{Dealing Cross-Sectional Dependence}

Cross-sectional dependence is one of the reasons of biased estimated in panel analysis [19]. Since Indian states are not independent they form a united whole called India. Therefore, there is all the possibility that to a certain extent they are mutually dependent on each other. Canning and Pedroni [20] propose that if we subtract time effect in the construction of panel statistics cross-sectional dependence is addressed [21]. Through above explained equation number one and four we calculate the time effect and for further panel analysis, this effect is subtracted. Therefore, we address the cross-sectional dependence by the methodology adopted by us.

\section{Data and Empirical Results}

Data for 33 states from 2000 to 2013 were taken from the Prowess database of the Centre for Monitoring Indian Economy (CMIE) [22]. The Prowess database is equivalent to the Compustat database for U.S [23]. This database provides a set of socio-economical variables including electricity consumption and per-capita income for all the states of India. Per-capita income is based on a constant Indian currency of the year 2004.

Table 1 and Table 2 list the causation regression results. We estimated all the equations (Equations (1) to (6)) by various estimation methods: (a) and (d) pooled panel, (b) and (e) individual fixed effects, and (c) and (f) individual random effects. According to the pooled panel regression (column (a) in Table 1), the estimated coefficient of lag EC is significant. This means that previous value of EC does have an influence on the income of the state. Similar results are found for individual fixed effect regression and individual random effect regression. Therefore, there is no difference between these three models. These results are consistent with the findings of [1] [2]. However, the Hausman test resulted in individual fixed model as the better model in comparison to the individual random for EC to income relationship. Therefore, we conclude fixed model as more trustworthy than random and EC as a significant cause of income generation. As a result, the increase in one unit of electricity consumption will result in Rs 13.4 increase in per capita income of the India.

Similar tests were conducted for reverse directional causality income to EC. In this case, results obtained are not consistent. Hausman test between the model (e) and (f) proved that random model is better than fixed. This model suggests that income significantly causes the increase in EC. One rupee increase in the per capita income will increase 0.32 unit of electricity consumption per year. Based on both the tests we conclude that fixed model for EC to income and random model for income to EC represents the reality of the Indian condition. Although the pooled model also gives similar conclusions but there are significant differences in the coefficient estimated. Since our estimation is more robust, we argue them to be more appropriate for policy purposes. Both the relationship found by us are totally consistent with the results of [7].

Based on the availability of data and as suggested by [24] causality analysis at disaggregated level of EC and income was conducted. EC was found for five purposes. These are domestic, commercial, light industry, heavy industry, and agriculture. For the purpose of analysis, a matrix was prepared for five variables and following 
Table 1.The EC and income (EC income).

\begin{tabular}{|c|c|c|c|c|c|c|}
\hline & (a) & & (b) & & (c) & \\
\hline & Pooled panel & t-value & Individual fixed & t-value & Individual random & t-value \\
\hline Constant & $-34,723.400^{* * *}$ & $(-47.173)$ & & & $-12,540.927^{* * *}$ & $(-41.392)$ \\
\hline lag (Income) & $0.450^{* * *}$ & (16.196) & $0.434^{* * * *}$ & (13.772) & $0.259^{* * *}$ & (17.793) \\
\hline $\operatorname{lag}(\mathrm{EC})$ & $31.100^{* * *}$ & (19.33) & $13.714^{* * *}$ & $(4.288)$ & $2.652^{* *}$ & (2.836) \\
\hline lag (ECT) & $0.731^{* * *}$ & (24.957) & $0.729^{* * *}$ & (16.794) & $0.229^{* * *}$ & (4.018) \\
\hline $\mathrm{R}^{2}$ & 95.939 & & 78.809 & & 90.565 & \\
\hline Adj. $R^{2}$ & 94.278 & & 66.527 & & 88.996 & \\
\hline
\end{tabular}

Signif. codes: 0 “***” 0.001 “**” 0.01 “"” 0.05 “.” 0.1 “” 1. Maddala-Wu Unit-Root Test-Stationary. Hausman Test-Individual fixed is better model.

Table 2. The income and EC (income EC).

\begin{tabular}{ccccccc}
\hline & \multicolumn{1}{c}{$(\mathrm{d})$} & & $(\mathrm{e})$ & & (f) \\
\hline & Pooled Panel & $\mathrm{t}$-value & Individual fixed & $\mathrm{t}$-value & Individual random & $\mathrm{t}$-value \\
\hline Constant & $-40,920.685^{* * *}$ & $(-59.554)$ & & & $-13,690.616^{* * * *}$ & $(-39.254)$ \\
$\operatorname{lag}$ (Income) & $0.960^{* * * *}$ & $(47.541)$ & 1.38616 & $(1.146)$ & $0.323^{* * *}$ & $(29.088)$ \\
$\operatorname{lag}$ (EC) & 0.670 & $(0.506)$ & -83.00889 & $(-0.432)$ & -0.326 & $(-0.579)$ \\
$\operatorname{lag}$ (ECT) & $0.731^{* * * *}$ & $(24.957)$ & 0.14632 & $(0.773)$ & $0.227^{* * *}$ & $(4.198)$ \\
$\mathrm{R}^{2}$ & 95.939 & & 1.6993 & & 90.343 & \\
Adj. $\mathrm{R}^{2}$ & 94.278 & & 1.4345 & & 88.779 & \\
\hline
\end{tabular}

Signif. codes: 0 “***” 0.001 “*” 0.01 “”” 0.05 “.” 0.1 “” 1. Maddala-Wu Unit-Root Test-Stationary. Hausman Test-Individual random is better model.

Equations (1)-(3) analysis were conducted. The result of the analysis suggested that individual fixed best represent the relationships. In accordance with individual fixed model electricity consumption for domestic, heavy industry, and agriculture is main antecedents of electricity consumption that caused the growth in GDP and not the commercial and light industry in case of Indian states. Maddala-Wu Unit-Root Test was conducted to check the stationarity of the series and the series was found to be stationary (Table 3).

\section{Conclusion}

Using panel data for 33 states from 2000 to 2013, and comparing pooled, fixed effect, and random effect models, we found evidence that the conclusions of the different models are not very consistent. For EC to income, the conclusion is converging, whereas, for income to EC there is divergence. Scrutinizing various models for India we found confirmation of bi-directional causality between electricity consumption and GDP. Furthermore, it is the increase in domestic and heavy industry electricity consumption that causes income growth and not the commercial, light industry, and agricultural electricity consumptions. The inconsistencies found in the earlier literature are because they have used a limited number of data points and not taken into account the diversity of India. Therefore, we conclude that study at the disaggregate level will give robust and conclusive findings not only because of the increased number of data points but also because of the removal of aggregation bias at the country level.

\section{Limitation and Future Direction}

Restricted availability of data for most of the developing countries is one of the biggest hurdles to conducting rigorous research based on these economies [25]. While conducting our research we also encountered the same problems. Availability of data for a limited number of years i.e. 2001 till 2013 is our biggest limitation. However, in the absence of data availability, there is no other option except abandoning the research project. Furthermore, there are researches that have concluded the causality even for a lesser number of years than of ours [26]. Research by E. Erdil and I. H. Yetkiner [26] conducted panel data causality analysis using data from 11 years from 1990 till 2000. Therefore, we concluded that we will proceed with the analysis of data from limited years rather 
Table 3. The income and disaggregate EC (EC income).

\begin{tabular}{ccccccc}
\hline & (d) & \multicolumn{3}{c}{ (e) } & \multicolumn{1}{c|}{ (f) } \\
\hline & Pooled panel & t-value & Individual fixed & t-value & Individual random & t-value \\
\hline Constant & $-38,223.006^{* * *}$ & $(-61.033)$ & & & $-11,061.072^{* * *}$ & $(-30.063)$ \\
lag (Income) & $0.309^{* * *}$ & $(11.369)$ & $0.261^{* * *}$ & $(4.877)$ & $0.112^{* * *}$ & $(4.954)$ \\
lag (EC_Domestic) & $169.24^{* * *}$ & $(14.599)$ & $134.782^{* * *}$ & $(4.670)$ & $54.307^{* * *}$ & $(6.586)$ \\
lag (EC_Commercial) & $38.246^{* *}$ & $(2.94)$ & -6.604 & $(-0.180)$ & -5.432 & $(-0.649)$ \\
lag (EC_Light Industry) & $-13.514^{* *}$ & $(-3.055)$ & 0.517 & $(0.072)$ & $-22.808^{* * *}$ & $(-5.016)$ \\
lag (EC_Heavy Industry) & $8.595^{* * *}$ & $(3.845)$ & $14.282^{*}$ & $(2.320)$ & 0.923 & $(0.597)$ \\
lag (EC_Agriculture) & 2.344 & $(0.723)$ & 16.113 & $(1.148)$ & $6.774^{* * *}$ & $(3.595)$ \\
lag (ECT) & $0.898^{* * *}$ & $(32.104)$ & $0.889^{* * *}$ & $(23.289)$ & $0.87^{* * *}$ & $(18.666)$ \\
$\mathrm{R}^{2}$ & 98.118 & & 87.967 & & 90.954 & 86.462 \\
Adj. R
\end{tabular}

Signif. codes: 0 “***” 0.001 “*”, 0.01 “”” 0.05 “.” 0.1 “” 1. Maddala-Wu Unit-Root Test-Stationary. Hausman Test-Individual fixed is better model.

than abandoning the project. We propose future researchers to study the causality directions for the disaggregated pair of electricity consumption to the GDP, so that the independent relationship of various forms of electricity consumption to GDP is obtained and that may put light on many inconsistencies found in present literature.

\section{Acknowledgements}

The author expresses sincere thanks to all the reviewers for their time and effort. The author offers special thanks to Nilesh Asnani who extended all his help to shape this project. Without whom this paper would never have been possible.

\section{References}

[1] Asafu-Adjaye, J. (2000) The Relationship between Energy Consumption, Energy Prices and Economic Growth: Time Series Evidence from Asian Developing Countries. Energy Economics, 22, 615-625. http://dx.doi.org/10.1016/S0140-9883(00)00050-5

[2] Masih, A.M.M. and Masih, R. (1996) Energy Consumption, Real Income and Temporal Causality: Results from a Multi-Country Study Based on Cointegration and Error-Correction Modelling Techniques. Energy Economics, 18, 165-183. http://dx.doi.org/10.1016/0140-9883(96)00009-6

[3] Gupta, G. and Sahu, N.C. (2009) Causality between Electricity Consumption \& Economic Growth: Empirical Evidence from India. Munich Personal RePEc Archive [Online]. https://mpra.ub.uni-muenchen.de/22942/1/MPRA paper 22942

[4] Soytas, U. and Sari, R. (2003) Energy Consumption and GDP: Causality Relationship in G-7 Countries and Emerging Markets. Energy Economics, 25, 33-37. http://dx.doi.org/10.1016/S0140-9883(02)00009-9

[5] Cheng, B.S. (1999) Causality between Energy Consumption and Economic Growth in India: An Application of CoIntegration and Error-Correction Modeling. Indian Economic Review, 1, 39-49.

[6] Abbas, F. and Choudhury, N. (2013) Electricity Consumption-Economic Growth Nexus: An Aggregated and Disaggregated Causality Analysis in India and Pakistan. Journal of Policy Modeling, 35, 538-553. http://dx.doi.org/10.1016/j.jpolmod.2012.09.001

[7] Paul, S. and Bhattacharya, R.N. (2004) Causality between Energy Consumption and Economic Growth in India: A Note on Conflicting Results. Energy Economics, 26, 977-983. http://dx.doi.org/10.1016/j.eneco.2004.07.002

[8] Mohanty, A. and Chaturvedi, D. (2015) Relationship between Electricity Energy Consumption and GDP: Evidence from India. International Journal of Finance \& Economics, 7, 186-202. http://dx.doi.org/10.5539/ijef.v7n2p186

[9] Cowan, W.N., Chang, T., Inglesi-Lotz, R. and Gupta, R. (2014) The Nexus of Electricity Consumption, Economic Growth and $\mathrm{CO}_{2}$ Emissions in the BRICS Countries. Energy Policy, 66, 359-368.

http://dx.doi.org/10.1016/j.enpol.2013.10.081

[10] Ozturk, I. (2010) A Literature Survey on Energy-Growth Nexus. Energy Policy, 38, 340-349. 
http://dx.doi.org/10.1016/j.enpol.2009.09.024

[11] Census Organization of India (2011) States Census 2011. Government of India. [Online] http://www.census2011.co.in/states.php

[12] United Nations (2016) 2015 Revision of World Population Prospects. United Nations.

[13] Beenstock, M. and Felsenstein, D. (2015) Estimating Spatial Spillover in Housing Construction with Nonstationary Panel Data. Journal of Housing Economics, 28, 42-58. http://dx.doi.org/10.1016/j.jhe.2014.10.002

[14] Stoker, T.M. (2008) Aggregation (Econometrics). In: Durlauf, S. and Blume, L., Eds., The New Palgrave Dictonary of Economics, Palgrave Macmillan, London.

[15] Rogerson, P.A. (1983) Comparisons of Aggregate Variable Forecasts Using Aggregate and Disaggregate Models. Socio-Economic Planning Sciences, 17, 373-380. http://dx.doi.org/10.1016/0038-0121(83)90043-5

[16] Karanfil, F. and Li, Y. (2015) Electricity Consumption and Economic Growth: Exploring Panel-Specific Differences. Energy Policy, 82, 264-277. http://dx.doi.org/10.1016/j.enpol.2014.12.001

[17] Odhiambo, N.M. (2009) Energy Consumption and Economic Growth Nexus in Tanzania: An ARDL Bounds Testing Approach. Energy Policy, 37, 617-622. http://dx.doi.org/10.1016/j.enpol.2008.09.077

[18] Granger, C.W.J. (1988) Some Recent Development in a Concept of Causality. Journal of Econometrics, 39, 199-211. http://dx.doi.org/10.1016/0304-4076(88)90045-0

[19] Kara, M., Nazlığlu, Ş. and Ağır, H. (2011) Financial Development and Economic Growth Nexus in the MENA Countries: Bootstrap Panel Granger Causality Analysis. Economic Modelling, 28, 685-693. http://dx.doi.org/10.1016/j.econmod.2010.05.015

[20] Canning, D. and Pedroni, P. (2008) Infrastructure, Long-Run Economic Growth and Causality Tests for Cointegrated Panels. The Manchester School, 76, 504-527. http://dx.doi.org/10.1111/j.1467-9957.2008.01073.x

[21] Liddle, B. and Lung, S. (2013) The Long-Run Causal Relationship between Transport Energy Consumption and GDP: Evidence from Heterogeneous Panel Methods Robust to Cross-Sectional Dependence. Economics Letters, 121, 524-527. http://dx.doi.org/10.1016/j.econlet.2013.10.011

[22] CMIE (2016) States of India. [Online]. http://www.cmie.com

[23] Chadha, A. (2009) TRIPs and Patenting Activity: Evidence from the Indian Pharmaceutical Industry. Economic Modelling, 26, 499-505. http://dx.doi.org/10.1016/j.econmod.2008.10.004

[24] Liddle, B. and Lung, S. (2015) Revisiting Energy Consumption and GDP Causality: Importance of a Priori Hypothesis Testing, Disaggregated Data, and Heterogeneous Panels. Applied Energy, 142, 44-55. http://dx.doi.org/10.1016/j.apenergy.2014.12.036

[25] Alper, C.E. (2002) Business Cycles, Excess Volatility, and Capital Flows: Evidence from Mexico and Turkey. Emerging Markets Finance and Trade, 38, 25-58.

[26] Erdil, E. and Yetkiner, I.H. (2009) The Granger-Causality between Health Care Expenditure and Output: A Panel Data Approach. Applied Economics, 41, 511-518. 